\title{
Effect of Alkali Treatment on Mechanical Properties of Agave Fibre Reinforced Polymer Composites
}

\author{
Pradeep Kumar $\mathbf{J}^{1}$, A.Sugunakar ${ }^{2}$, Chetty.Nagaraj ${ }^{3}$ \\ ${ }^{1}$ Assistant Professor, Department, of mechanical Engineering, St .Peter's Engineering College, Maisammaguda \\ (V), Medchal (M).Hyderabad.500014, Telangana, India. \\ ${ }^{2}$ Assistant Professor, Department, of mechanical Engineering, Vivekananda institute of technology\& science, \\ Karimnagar,505001, Telangana, India. \\ ${ }^{3}$ Assistant Professor, Department, of mechanical Engineering, CMR Technical Campus Kandlakoya(V), \\ Medchal (M), Hyderabad-501401, Telangana, India.
}

\begin{abstract}
The present work study flexural and tensile behavior of short AGAVE fiber reinforced composites. The fibers are chemically treated in $10 \% \mathrm{NaOH}$ solution at room temperature. Short fibers of $7 \mathrm{~mm}, 10 \mathrm{~mm}$ and $12 \mathrm{~mm}$ are used in the present work. The composite lamina is prepared by hand molding using isopthalic polyester resin. Flexural test and tension tests are carried out as per ASTM standards. The flexural strength and tensile strength of composite lamina are evaluated. The Effect of Fiber surface Treatment on flexural and tensile properties are observed. Surface modification of the fibre by alkali treatment improves the chemical bonding and tensile strength. An interact between fiber and matrix was observed from the SEM (scanning electron microscope) micrographs.
\end{abstract}

Keywords: Natural fibres, Agave, reinforced polymer, tensile test, hand layup technique.

\section{Introduction}

For making advanced composites the natural fibre are being used instead of glass fibre and carbon fibres. The interest of industry is growing in natural fibre reinforced composites for industrial and research applications . Natural fibers are found superior to the artificial fibers with the properties like less weight, low density, eco-friendly, high specific strength etc..A combination of properties of some natural fibers including low cost, low density, non-toxicity, no abrasion during processing and recyclability has arisen more interest for the manufacturing industry of low cost and low weight composites [1-2]. physical and mechanical properties of natural fibers are mainly depends on their physical composition such as structure of fibers, cellulose content, angle of fibrils and cross section. Their biodegradability can contribute to a healthy ecosystem while their low cost and high performance fulfills the economic interest of industry [3-4]. The tensile and flexural properties of the green composites with different pineapple fiber content and compared with the virgin resin[5]. Composite are those material made up from two or more distinct materials having different chemical and physical properties provide a well defined structure [6]. The effect of alkali treatment on the mechanical and thermal properties of hemp fiber-reinforced polyester composites are investigated[7]. The chemical modification of flax fiber by alkali treatment. The study concentrated on optimizing parameters, such as time and concentration of $\mathrm{NaOH}$, to develop a continuous process for the treatment and fabrication of unidirectional flax fiber epoxy composites[8]. The Effects of different chemical modifications on the properties of flax fiber-reinforced rotationally molded composites. The chemical modifications carried out were mercerization, peroxide treatment, benzoylation, and peroxide treatment[9]. the effect of chemical modification on the tensile strength of flax fibers. The authors tried acetylation and stearation and found that the tensile strength of flax fibers did not exhibit any drastic improvement[10]. Different methods for chemical modification of natural fibers so as to incorporate water repellency, resistance towards chemicals and better mechanical properties, have been discussed[11]. The tensile, flexural, and impact behavior of PALF-reinforced polyester composites as a function of fiber loading, fiber length, and fiber surface modification are investigated. The tensile strength and Young's modulus of the composites were found to increase with fiber content in accordance with the rule of mixtures[12]. 


\section{a) Fibre Extraction from Plant}

\section{Methodology}

To extract the fibre, the mature Agave leaves were collected from the wild. Then the thrones on the leaf margins and the tip were removed. Then the leaves were sun dried for two days to remove excess moisture. Then wetting of the leaves was carried out by immersing them in water for minimum two weeks. This facilitated maceration of the fleshy layers of the leaves. The wetted leaves were then manually beaten to remove the flesh. The cured fibres were then thoroughly washed and combed to free the flesh and was air dried for two to three days at room temperature. The dried fibres were thinned by ramming it in order to remove the unwanted short and broken fibres. The entire fibre extraction process took 20-25 days.

\section{b) Alkali treatment of fibre}

Alkalization is a common pre-processing technique used on base natural fibre to remove hemicellulose, fats and waxes that may reduce the interfacial strength when processed into composite form. The raw Agave fibre was washed with water for several times and dried at room temperature for 48 hours. The surface modification consisted of alkali treatment of fibre with varying concentration of $\mathrm{NaOH}$. It was found that with varying $\mathrm{NaOH}$ concentration, the fibre property changes. The raw fibres were treated and immersed with $5 \%$, $10 \%$ and $15 \%$ sodium hydroxide solution for 30minutes and then washed with very dilute hydrochloric acid $(\mathrm{HCl})$ to remove the residual alkali. Then, the fibres were rinsed with cold water two or thrice. The rinsed fibres were dried at room temperature for 2 to 3 days.

\section{c) Polyester Resin}

Unsaturated polyesters are extremely versatile in properties and applications and have been a popular thermoset used as the polymer matrix in composites. The matrix used in this study was unsaturated polyester. It is viscous liquid, transparent, thermosetting polymer type. The liquid converts to solid by adding hardener additives methyl-ethyl-ketone-peroxide (MEKP), which is transparent liquid with $2 \%$ for each 100gm of UPE at room temperature.

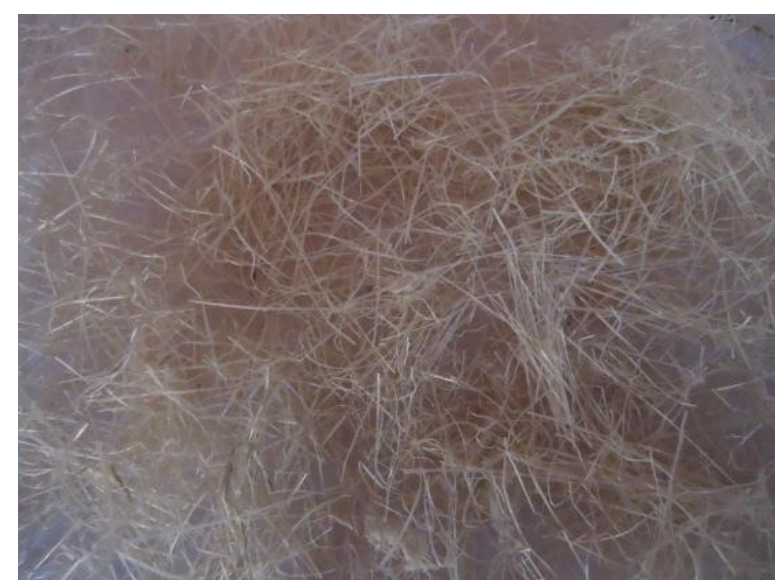

Figure 1 Agave fibre (a) Raw

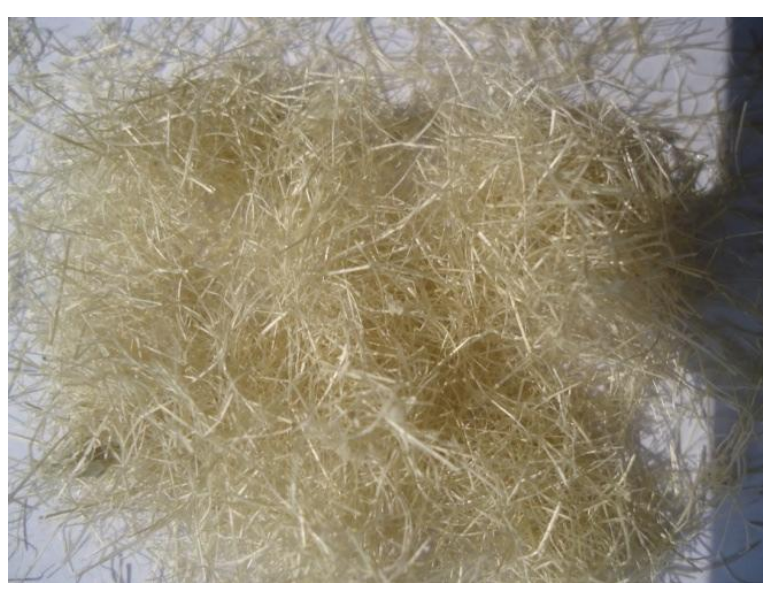

and (b) alkali treated

Table 1. Properties of Polyester Resin.

\begin{tabular}{|c|c|c|c|}
\hline Sno & Properties & Value & Unit \\
\hline 1 & Appearance & Colorless to pale yellow liquid & \\
\hline 2 & Specific gravity & $1.12 \pm 0.01$ & $\mathrm{~g} / \mathrm{cm} 3$ \\
\hline 3 & Viscosity & $450 \pm 50$ & $\mathrm{Cp}$ \\
\hline 4 & Tensile Strength & 7300 & $\mathrm{MPa}$ \\
\hline 5 & Tensile Modulus & 5.3 & $\mathrm{GPa}$ \\
\hline 6 & Flexure Strength & 15,250 & $\mathrm{MPa}$ \\
\hline 7 & Flexure Modulus & 6.27 & $\mathrm{GPa}$. \\
\hline
\end{tabular}




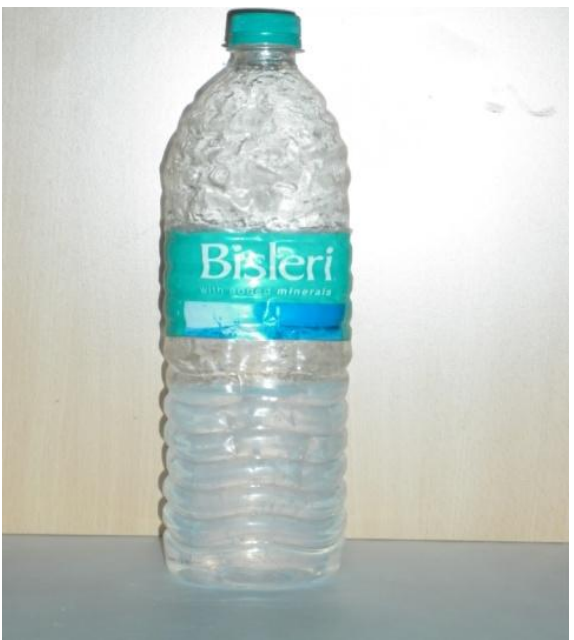

Fig 2 a) PVA

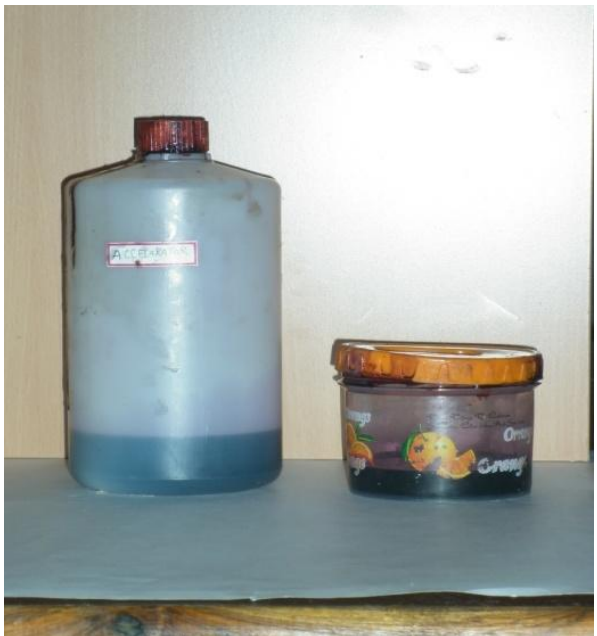

b) Cobalt napthanate $\&$ Catalyst

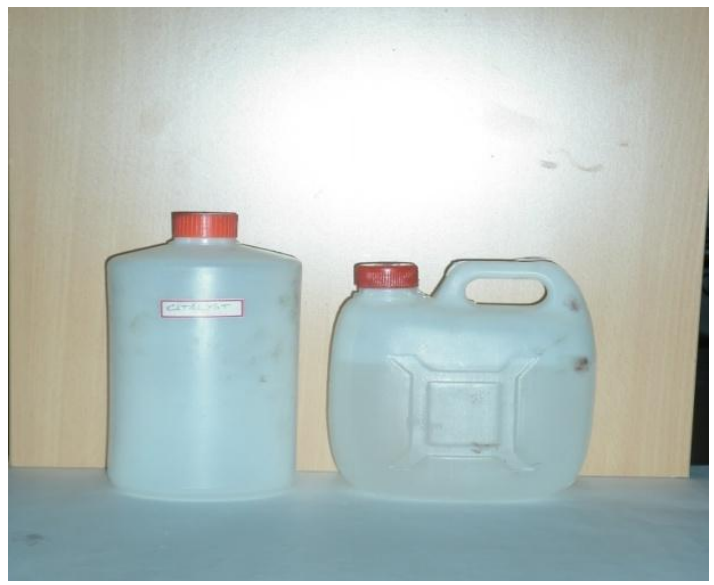

c) Catalyst

\section{d) Specimen preparation}

Wax polish is applied on the surfaces of the base plates and poly vinyl alcohol (PVA) is applied with a brush and allowed to dry for few minutes to form a thin layer. These two items will help in easy removal of the laminate from the base plates. PVA also provides a glossy finish to the surfaces of the laminate. The unsaturated general purpose isopthalic resin is taken along with $2 \%$ of accelerator- Cobalt napthanate and catalyst-methyl ethyl ketone peroxide (MEKP). The weight of the resin is 6 times the weight of the fiber taken for the composite. The catalyst initiates the polymerization process and the accelerator speeds up this process. Initially the accelerator is added and next the catalyst is added. The contents are thoroughly stirred and then placed on the base surface and spread uniformly with the brush. It is always preferable to add lesser quantity of accelerator than the specified amount of accelerator to avoid solidification of the contents before they are placed and spread on the glass plate. Then the top base plate that was already applied with the wax and PVA is placed and a weight of about $1000 \mathrm{~N}$ is placed over for about 5 hours.

Various sample composite sheets are moulded using different additives to the basic ingredient, i.e., Polyester. Different additives are: accelerator- Cobalt napthanate \& Catalyst treated agave short fiber (TF), untreated agave short fiber (UTF). The variety of composites produced and respective ingredients are indicated in the following.

i. Polyester + Cobalt napthanate \& Catalyst $+7 \mathrm{~mm} 0.5 \mathrm{~g}$ UTF

ii. Polyester + Cobalt napthanate $\&$ Catalyst $+7 \mathrm{~mm} 0.5 \mathrm{~g} \mathrm{TF}$

iii. $\quad$ Polyester + Cobalt napthanate $\&$ Catalyst $+10 \mathrm{~mm} 0.5 \mathrm{~g}$ UTF

iv. Polyester + Cobalt napthanate \& Catalyst $+10 \mathrm{~mm} 0.5 \mathrm{~g}$ TF

v. Polyester + Cobalt napthanate \& Catalyst $+12 \mathrm{~mm} 0.5 \mathrm{~g}$ UTF

vi. Polyester + Cobalt napthanate \& Catalyst $+12 \mathrm{~mm} 0.5 \mathrm{~g}$ TF 
The specimen of untreated chopped Agave fibre reinforced Polyester composite with three different fibre lengths such as $7 \mathrm{~mm}, 10$ and $12 \mathrm{~mm}$ were prepared in the laboratory using hand layup and compression mould technique. Similarly the specimen of alkali treated chopped Agave fibre reinforced Polyester composite with three different fibre lengths such as $7 \mathrm{~mm}, 10 \mathrm{~mm}$, and $12 \mathrm{~mm}$ were prepared. The specimens were prepared with a fibre resin ratio of 35:65 by manual stirring for a sufficient time to scatter the fibres in the matrix .

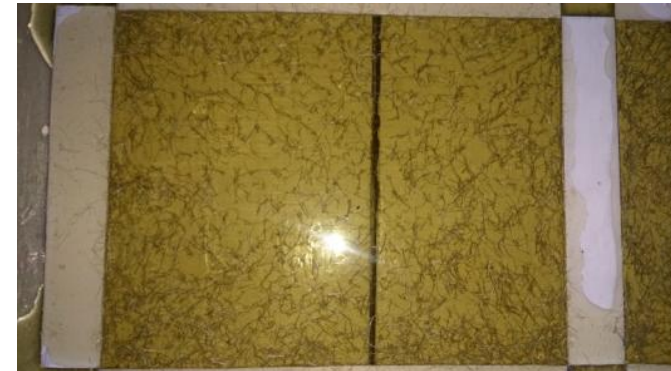

Fig 3 a) Chopped untreated Agave fibre

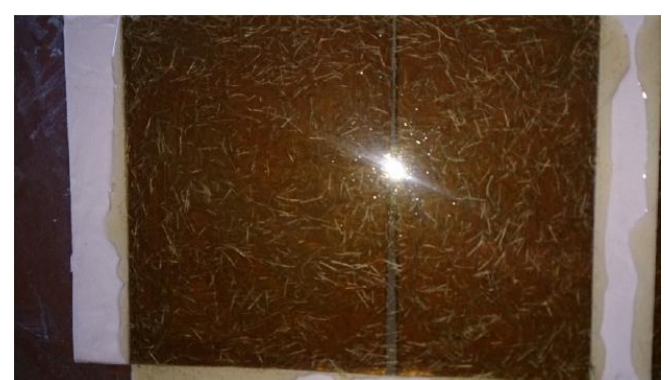

b) Chopped alkali treated Agave fibre

\section{a) Tensile test}

\section{Experimental}

Tensile testing of specimen prepared according to ASTM D 638, was carried out using electronic tensile testing machine of cross head speed of $5 \mathrm{~mm} / \mathrm{min}$ and a gauge length of $50 \mathrm{~mm}$. The tensile modulus and elongation at the break of the composites were calculated from the load displacement curve. At least five specimens were tested for each set of samples and the mean values were reported.

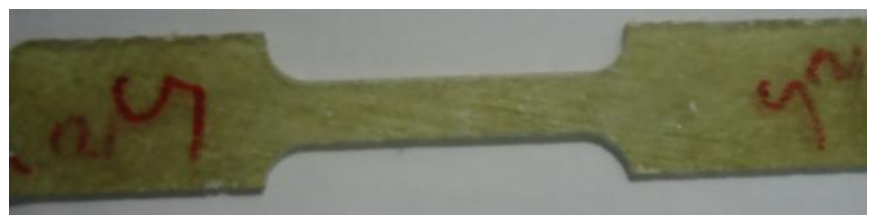

Fig 4 Tensile Test Specimen

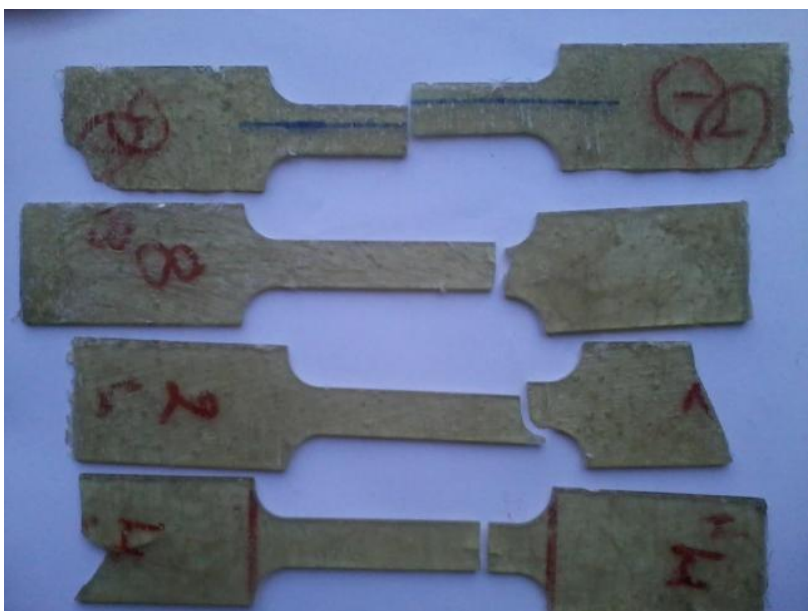

Fig 5 Tensile Test Specimens after Testing

The effect of the alkali treatment on the tensile performance of the Agave fibre polyester composites with different fibre lengths was investigated. The load verses elongation curves was plotted between treated and untreated fibres. Different fibre lengths was chosen i.e. $7 \mathrm{~mm}, 10 \mathrm{~mm}, 12 \mathrm{~mm}$. 


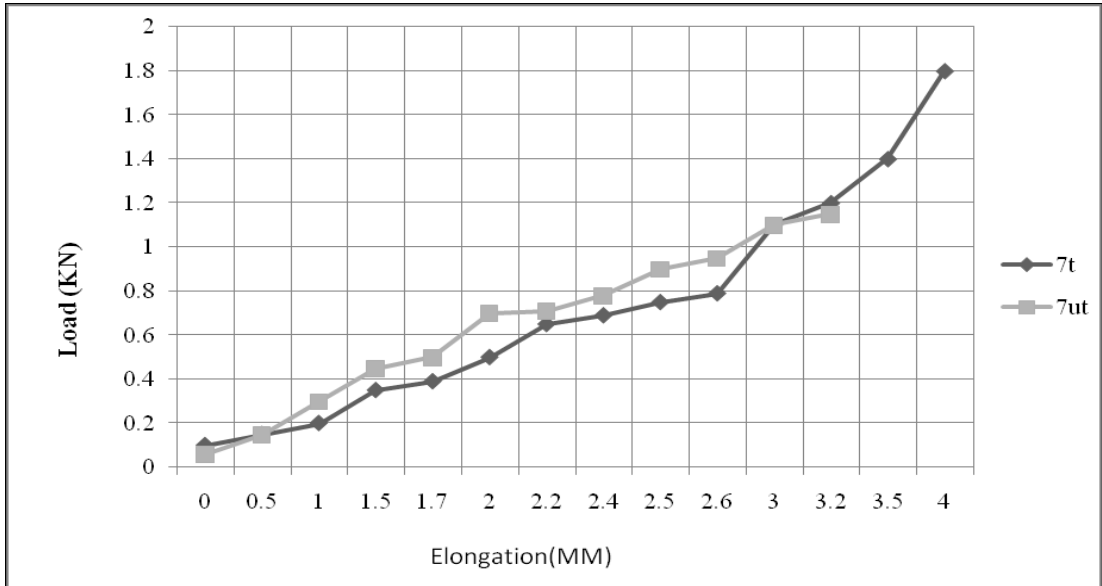

Fig 6 Load vs Elongation curve between $7 \mathrm{~mm}$ treated \& untreated fibre composites

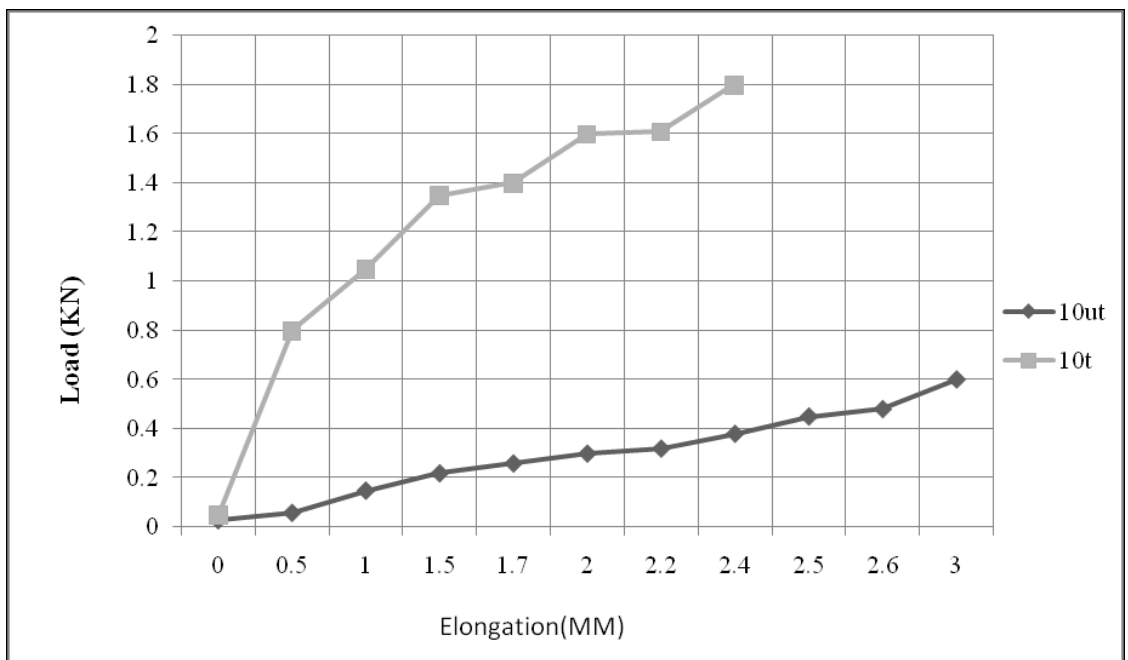

Fig 7 Load vs Elongation curve between 10mm treated fibre \& untreated fibre composites

\section{b) SEM Analysis}

Scanning electron micrographs (SEM) of resin sample and its respective composites were taken on Leo 435 VP. Figure $9 \& 10$ is the micro graphs of the $7 \mathrm{~mm}$ agave fibre reinforced polymer composite which is subjected to tensile test. Micrographs clearly show that no debonding, no fiber chipping out and no crack formation it shows that the bonding is strong between the matrix and reinforcement.

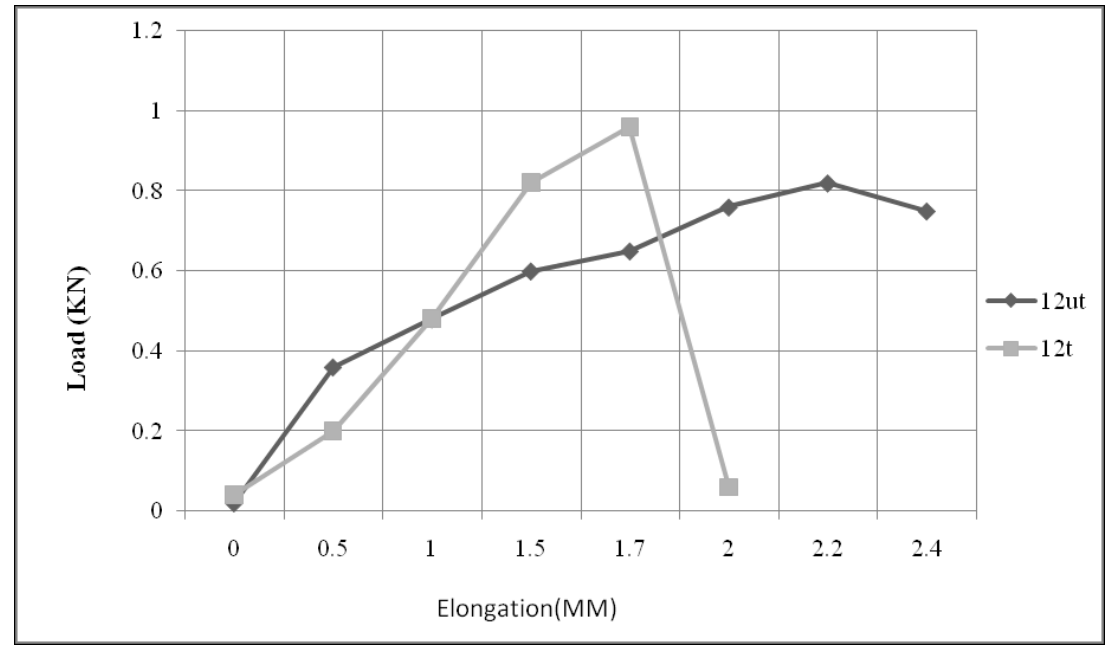

Fig 8 Load vs Elongation curve between $12 \mathrm{~mm}$ treated \& untreated composite 

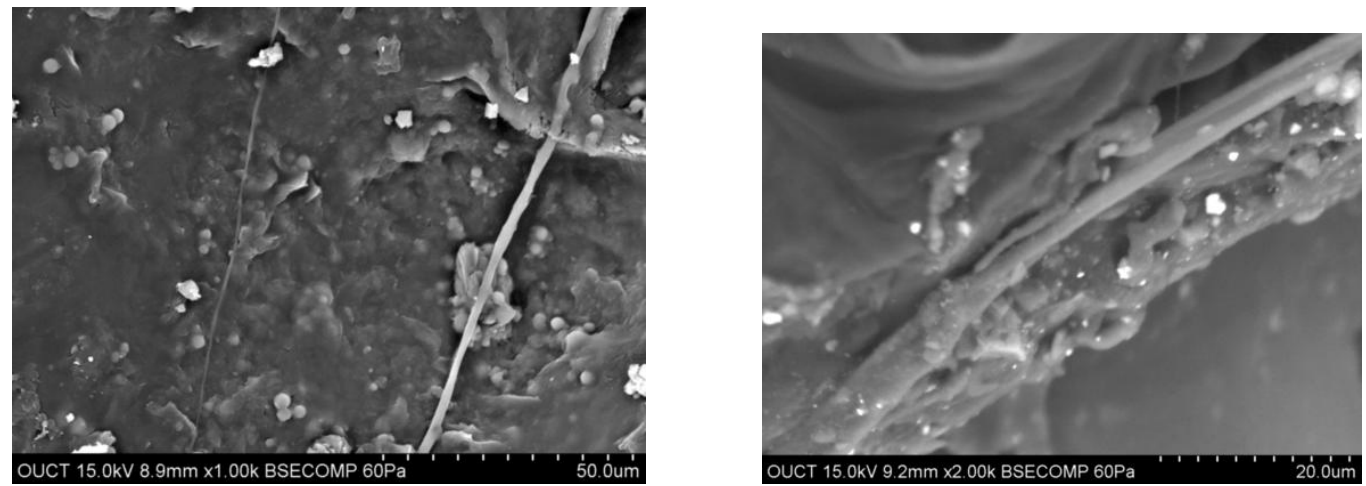

Fig 9 SEM images of $7 \mathrm{~mm}$ untreated and treated fibres before testing
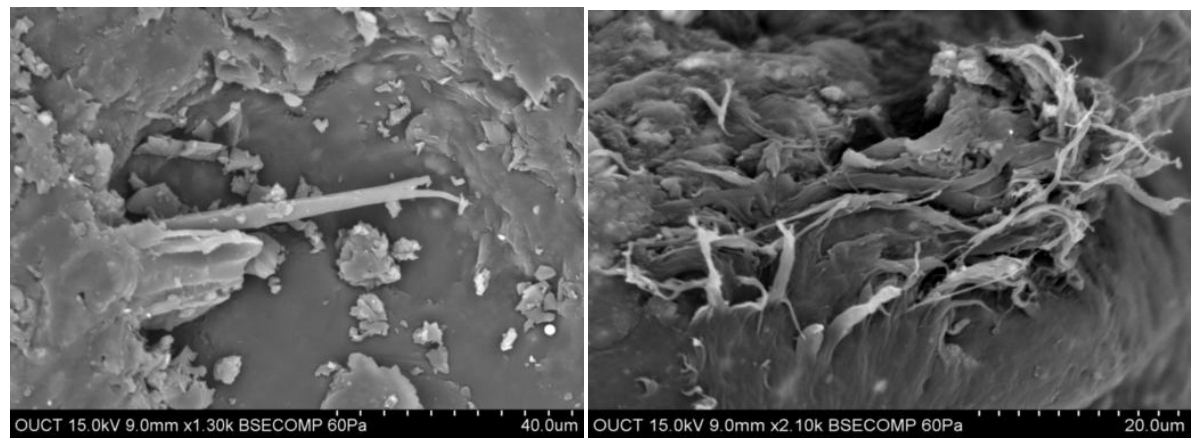

Fig 10 SEM images of $7 \mathrm{~mm}$ untreated and treated fibres after testing

\section{Conclusion}

The present work deals with the preparation of characterization of agave fiber reinforced polymer composite.

The mechanical behavior of the composite lead to the following conclusions

1. With the alkaline treatment the chemical bonding improved between fibre and matrix.

2. When the fibre is treated the tensile strength increases by $10 \% .10 \mathrm{~mm}$ fibre length composites exhibit good results.

3. Adhesion at fibre-matrix interface can be improved by chemical modification (sodium hydroxide treatment - mercerization) of the fibres. This makes them more porous leading to a rough surface texture allowing the agave fibres to reinforce strongly with polyester matrix.

4. SEM observation reveals that most of the fibers were broken instead of pulling out from the matrix

\section{References}

[1]. A. K. Bledzki and J. Gassan, "Composites Reinforced with Cellulose Based Fibres," Progress in Polymer Sci-ence, Vol. 24, No. 2, 1999, pp. 221-274.

[2]. P. J. Herrara-Franco and A. Valadez-Gonzalez, "Me-chanical Properties of Continuous Natural Fibre-Rein- forced Polymer Composites," Composites Part A: Applied Science and Manufacturing, Vol. 35, No. 3, 2004, pp. 339-345.

[3]. Jayaramudu J., Obi Reddy K., Uma Maheswari C., Jeevan Prasad Reddy D., VardaRajulu A., Journal of Reinforced Plastics and Composites 28 (2009) 2177-2181.

[4]. Ashok Kumar, M., Ramachandra Reddy, G., Hemachandra Reddy K., Venkata Mohana Reddy Y., Ranga Reddy P., Subbarami Reddy N., Indian Journal of Material Science 23 (2011) 345-250.

[5]. Jindal R, Kaith BS, Mittal H, and Sharma R, Advances in Applied Science Research, 2 (2):19-27 (2011).

[6]. Aziz SH and Ansell MP, Compos. Sci. Technol., 64:1231 (2004).

[7]. Weyenberg IV, Truong TC, Vangrimde B, and Verpoest I, Compos. A, 37:1368 (2006).

[8]. Wang B, Panigrahi S, Tabil L, and Crerar W, "Effects of Chemical Treatments on Mechanical and Physical Properties of Flax Fiber-reinforced Rotationally Molded Composites,'”in ASAE Annual Meeting, Paper no. 046083 (2004).

[9]. Zafeiropoulos NE, Dijon GG, and Baillie CA, Compos. A, 38: 621 (2007).

[10]. Rakesh Kumar, Sangeeta Obrai1,Aparna Sharma," Chemical modifications of natural fiber for composite material", Pelagia Research Library Der Chemica Sinica, 2011, 2 (4):219-228.

[11]. L. Uma Devi, S. S. Bhagawan, Sabu Thomas," Mechanical Properties of Pineapple Leaf Fiber-Reinforced Polyester Composites", John Wiley \& Sons, Inc. CCC 0021-8995/97/091739-10, 1997.

[12]. Herakovich, C.T., "Mechanics of fibrous composites". New York: Wiley; (1998). p. 1- 27.

[13]. Berghezan, A.," Nucleus", 8(5), 1966, (Nucleus an Editeur, 1, rhe, Chalgrin, Paris,) 16(e). 
[14]. Agarwal B.D., and Broutman L.J., "Analysis and performance of fiber composites" John Wiley \& Sons, NewYork, (1980): p. 3-12.

[15]. Mallick P.K. 1993. Fiber Reinforced Composite: Materials, Manufacturing And Design, Second Edition, 18, Marcel Dekker Inc, Newyork,

[16]. Abdul Khalil M., Abu Bakar A., Mariatti M., Jannah, H. P. S. 2008. Properties of Banana and Pandanus Woven Fabric Reinforced Unsaturated, Polyester Composites, Journal of Composite Materials, 42 (9), pp.931-941

[17]. Santos C.J.E. 2009. Development of Fiber Reinforced Composite for Structural Applications, Submitted in partial fulfillment of course requirements for MatE 198B.

[18]. Rong, M.Z., Zhang, M.Q., Liu, Y., Yang, G.C. and Zeng, H.M., 2001, "The effect of fiber treatment on the mechanical properties of unidirectional sisal-reinforced epoxy composites," Compos. Sci. Technol., 61; pp. 14371447.

[19]. Wambua P., Ivens J, Verpoest I., 2003, "Natural fibers: can they replace glass in fiber reinforced plastics, Compos Science Technology"; 63: 1259-64.

[20]. Schuh TG., "Renewable materials for automotive applications". Http // www. Ienica. net / fibers seminar/schuh.pdf (Accessed in February 2006). 